\title{
Sicilian Cannoli of Enhanced Stability
}

\author{
Antonino Scurria, ${ }^{a}$ Pietro Genco, ${ }^{b}$ and Mario Pagliaro ${ }^{*}, a$ \\ ${ }^{a}$ Istituto per lo Studio dei Materiali Nanostrutturati, CNR, via U. La Malfa 153, 90146 Palermo, Italy \\ ${ }^{b}$ Morsi di Sole Dei Fratelli Genco, via S. Francesco 58, 91029 Santa Ninfa TP, Italy
}

E-mail: mario.pagliaro@cnr.it (M. P.)

\begin{abstract}
Usually filled with a whey cheese-based sweet cream a few minutes before serving in order to prevent the moisture of the cream from softening the waffle and thus preserve its crispness, Sicilian cannoli are an ancient pastry of Sicily widely appreciated across the world. Another method to protect the "scorza" from quick softening is to coat the inner surface of the waffle with melt chocolate, altering the original taste of the pastry. We now report a simple method to stabilize Sicilian cannoli against moisture migration based on coating the inner layer of the waffle with a thin layer of pure glycerol.
\end{abstract}

Keywords Sicilian cannoli, ricotta pastry, whey cheese, glycerol, bioeconomy

\section{Introduction}

Consisting of tube-shaped shells of fried pastry dough filled with a sweet cream comprised of ricotta and 30\%-50\% sugar (sucrose), Sicilian cannoli are "the best known Italian dessert around the world. ${ }^{[1]}$ The name "cannolo" ("little tube") refers to the river cane ("canna" in Italian) used for several centuries to roll the dough to make the "scorza" (fried dough). The shell ("scorza") is prepared using a dough made with flour, lard, sugar and wine (generally Marsala, but in certain recipes also vinegar). Cut in discs, the risen dough is stretched and, today, rolled on steel cylinders and finally fried in lard or seed oil until an even browning is achieved.

From Canada through Brazil, where Sicilian immigrants brought the tradition to make cannoli from homeland, Sicilian cannoli today can be found in many countries across the world. ${ }^{[2]}$ As of late 2021, an internet search using the query "Sicilian cannoli" on a search engine returned 170,000 results. ${ }^{[3]}$ Similarly, the achievements of a Sicilian team who launched into stratosphere (up to $29,768 \mathrm{~m}$ ) a polymeric model of the pastry attached to a helium-filled balloon equipped with two videocameras recording images of the model cannolo above the clouds, in 2014 attracted global press coverage. ${ }^{[4]}$

Several companies in Sicily manufacture the waffles of cannoli on industrial scale. The waffles are generally sold to confectionary companies where the Sicilian cannoli are usually made "on demand". In other words, the cannoli are filled with the whey cheese-based cream a few minutes before serving in order to prevent the moisture of the sheep "ricotta" (whey cheese) from softening the waffle ("scorza") and thus preserve its crispness. Chiefly used in eastern Sicily, another method to protect the "scorza" from quick softening is to coat its inner surface with melt chocolate. ${ }^{[5]}$ This approach, however, inevitably impacts the original taste of the pastry.

To the best of our knowledge, only one study published in 2009 suggests a chemical route - to apply three layers of a zein-based coating to the waffle - to delay moisture migration from the ricotta to the waffle and to "prevent rapid pastry softening". ${ }^{[6]}$ More in detail, scholars based in Italy devised a combined approach to extend the shelf life of cannoli using ricotta functionalized with antimicrobial lemon extract (at 2,000 ppm optimal concentration), packaging the cannoli protected from zein and lemon extract in microperforated films of enhanced barrier properties. This approach eventually allows to prolong the cannoli's shelf life from less than two days for the untreated cannoli to more than three days for the functionalized cannoli. ${ }^{[6]}$

For pastry shops unwilling to use three layers of zein, namely the prolamin protein fraction of corn, insoluble in water and capable to form an hydrophobic layer resistant to microbial attack on coated food matrices, ${ }^{[7]}$ the problem remains: how to protect the freshly prepared Sicilian cannoli from rapid softening?

"One of the most important characteristics of a very good Cannolo" reads the cooking literature, "is the balance between the crispness of its container, the 'scorza', and the softness of its filling, the 'farcitura'. The right combination of these two different textures is a fundamental feature of this pastry, something that must be achieved and preserved at all costs, especially by preventing the moisture of ricotta cheese from softening the waffle. That's why the best Cannoli should be filled just a few minutes before they are served". ${ }^{[8]}$

Asked by one of the co-authors (P. G.) how to solve this old problem we reasoned that, rather than using an hydrophobic coating between the humid and the dry part of the cannolo, moisture migration from the cream to the inner layer of the crust could rather be achieved by using an edible hydrophilic coating.

\section{Results and Discussion}

The main ingredient for the filling of a cannolo is ricotta, preferably obtained starting from sheep's milk whey. Ricotta, however, is not a cheese, but rather a dairy product obtained by heating the whey to $80-82{ }^{\circ} \mathrm{C}$. Addition of a small amount of organic acid catalyzes the flocculation of proteins which start floating on the whey surface. Heating is interrupted and the clotted proteins are collected after 15-20 min using perforated ladle and transferred into conic plastic baskets to drain. ${ }^{[9]}$ Beyond $70 \%-80 \%$ water, the average composition of sheep ricotta is $10 \%-25 \%$ fat and $8 \%-10 \%$ protein.

Whey, namely the protein-rich yellowish liquid expelled from cheese curds during the cheese-making process, is particularly rich in proteins involved in response to and regulation of immunity and inflammation, providing many additional health benefits beyond simple nourishment. ${ }^{[10]}$ The milk proteins involved in the formation of the ricotta are the whey proteins, 
particularly abundant in the sheep's milk in the form of $\beta$-lactoglobulin, $\alpha$-lactalbumin, ovine serum albumin and immunoglobulins. ${ }^{[11]}$ The latter proteins, especially when cooked (denaturated), are well known emulsifiers, better than milk protein (casein). ${ }^{[12]}$

We decided therefore to treat the inner part of the cannoli crust with glycerol in order to increase the surface hydrophilicity using a small amount of a sweet edible substance today almost entirely obtained from vegetable oils as main by-product of the biodiesel and fatty acid/alcohol manufacturing. ${ }^{[13]}$ In detail, we coated the inner part of several waffles prepared according to a 1932 recipe kindly donated by a confectionary shop (Bar Mistral, Palermo, Italy) with a thin layer of pure glycerol, simply using a small brush previously immersed in glycerol of high purity $(99.5 \%$, Sigma-Aldrich, Milan, Italy). Coating was continued until an uniform, translucent thin coating was evident on the whole inner surface of the crust.

The broad absorption signal at $3500-3200 \mathrm{~cm}^{-1}$ due to the $\mathrm{O}-\mathrm{H}$ stretch (hydrogen bonded) in the FTIR spectrum in Figure 1 of the treated and untreated crusts recorded via the attenuated total reflection (ATR) sampling technique using a Nicolet iS 5 FTIR spectrometer (Thermo Fisher Scientific, Waltham, MA, USA) with an ATR iD7 cell, shows that even with an ultrathin layer such as that deposited by single brushing, the surface hydrophilicity of the pastry crust treated with glycerol is significantly enhanced in comparison to the crust of an untreated cannolo.

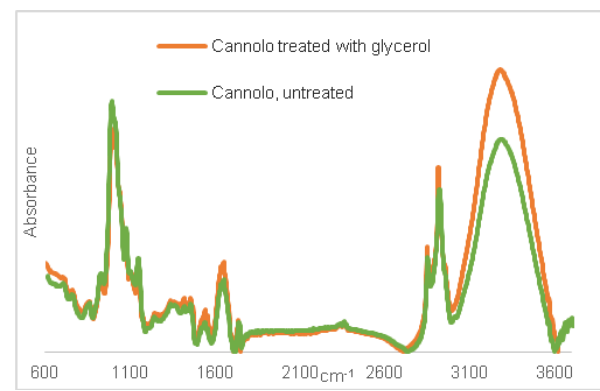

Figure 1 ATR FTIR spectrum of a cannolo crust treated with pure glycerol a few $\mathrm{h}$ after treatment (orange curve), and of a cannolo crust as such (green curve).

Figure 2 shows evidence that the original appearance of the crust after treatment with glycerol is entirely retained. The translucid apperance of the as-treated cannolo is rapidly lost, as glycerol acts as humectant rapidly hydrating the coated surface. ${ }^{[14]}$

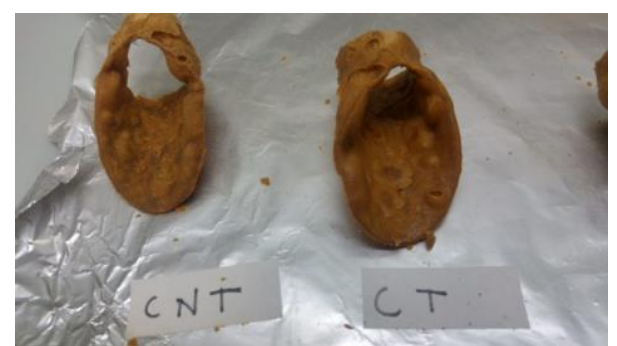

Figure 2 A sample of cannolo crust as received (left) and treated with pure glycerol (right).

Both the treated and the untreated cannoli were thus stuffed with the same whey cheese cream (gift of Bar Mistral, Palermo, Italy) and left at room temperature for $12 \mathrm{~h}$ prior to qualitative tests. A panel comprised of three members tasted the two cannoli and, invariably, found that only the treated cannoli met "the Golden Rule of cannoli", namely that the crust and ricotta should melt in your mouth at the same time". ${ }^{1]}$

Further evidence of the successful action of the glycerol thin layer at the crust/cream interface is shown by the video recorded

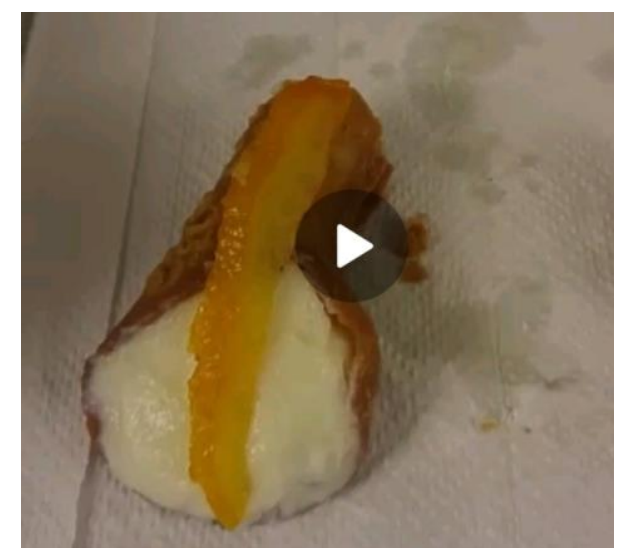

Figure 3 An untreated cannolo ( $C 5$ in the video) and cannolo treated with glycerol (C6) after $12 \mathrm{~h}$ stuffing with ricotta cream. The video can be watched at the URL: https://bit.ly/364sbEK.

$12 \mathrm{~h}$ after the cannoli preparation hyperlinked in Figure 3 and accessible at the URL: https://bit.ly/364sbEK.

The conventional cannolo was found to be soft and unable to resist manipulation with metal tweezers. On the contrary, the "scorza" of the cannolo treated with glycerol retained most of the original crispness. Subsequenly, we prepared new Sicilian cannoli treated with glycerol and compared their taste and stability with conventional cannoli concomitantly prepared using the same whey cheese cream. After $180 \mathrm{~min}$, we attempted to cut the two cannoli with a knife.

The conventional cannolo had partly lost its crispness. During cutting this cannolo was found to be mechanically unstable, affording several crust pieces as displayed in the video of the experiment at the URL: https://bit.ly/2Qtbyfo. On the other hand, the cannolo treated with glycerol was found to be mechanically stable, affording two neatly cut parts as shown by the video at the URL: https://bit.ly/2Sw0b9a.

The latter cannolo was tasted by a panel of three members and was found to retain its original crispness along with good flavor and taste.

In brief, forming a thin molecular layer of hydrophilic glycerol and water molecules at the inner surface of the crust, glycerol lowers the rate of water molecules diffusion from the sugared whey cheese cream to the crust, which is proportional to the difference in water concentration within the cream and at the crust surface. Furthermore, we make the hypothesis that glycerol adsorbed at the inner surface of the crust also lowers the emulsifying power of cooked whey protein molecules following $\beta$-lactoglobulin adsorption at the fried dough/ricotta cream oil-water interface. ${ }^{[15]}$ The latter effect would prevent the triglyceride emuslfication and removal of the oil from the fried dough, further lowering the rate of water molecules penetration in the fried crust.

\section{Conclusions}

In summary, we have discovered a new method to stabilize Sicilian cannoli against softening due to moisture migration from the whey cheese ("ricotta") cream to the crust. It is enough to treat the inner part of the crust with a small amount of glycerol, a biobased alcohol, to increase the surface hydrophilicity and achieve a substantial improvement in the crust ("scorza") stability upon prolonged contact with the sugared cream.

A safe and edible substance today nearly entirely obtained from vegetable oils as main by-product of biodiesel and fatty acid manufacturing, ${ }^{[13]}$ glycerol is a safe sweetener widely employed (also as humectant) by the food and beverage industry. ${ }^{[16]}$ These findings therefore establish a safe new method to stabilize an ancient pastry known since the early days of Roman civilization. 
For instance, Cicero at that time (76-75 BC) Roma's quaestor in Sicily, wrote about cannoli ("tubus farinarius, dulcissimo, edulio ex lacte factus", a definition found again in the first Sicilian-Italian-Latin dictionary published in 1751). ${ }^{[17]}$ We have named the new, moisture-protected cannolo "Ruggero", after Sicily's first king, Roger II, crowned in Palermo on December 25 $1130 .^{[18]}$

Further research in sensory experiment and stability mechanism will expand the understanding of the newly discovered effect of glycerol adsorbed on the inner surface of Sicilian cannoli waffle.

It is also relevant, in conclusion, to notice that a finding of significant socioeconomic relevance for Sicily originates from an innovative new use of a biobased substance obtained in over 4 million t/a amount (and counting) from biological resources. ${ }^{[13,14]}$ This in its turn provides another example of the urgency to establish in Sicily a new bioeconomy research and educational centre of international standing. ${ }^{[19]}$

\section{Acknowledgements}

This study is dedicated to the memory of Dr. Lorenzo Savoja, chemist and beloved schoolmate of one of us (M. P.). We are indebted to Michele and Ron Garofalo (Bar Mistral, Palermo, Italy) for a generous gift of Sicilian cannoli waffles and whey cheese cream which helped us to conduct the experiments. We thank Dr. F. D'Agostino (Istituto per lo Studio degli Impatti Antropici e Sostenibilità in ambiente marino, CNR, Capo Granitola, Campobello di Mazara, Italy) for allowing us to conduct the FTIR measurements.

\section{Author Contributions}

Following are the details of the contributions made by each of the authors for the manuscript: P. G. carried out the first experiments using glycerol to coat the cannoli's waffle. A. S. carried out systematic experiments including the FTIR investigation. M. P. conceived the experiments and wrote the manuscript.

\section{Author Information}

ORCID: A. S. (0000-0001-5624-6833), M. P. (0000-00025096-329X)

\section{Conflict of Interest}

The authors declare no conflict of interest.

Copyright (c) 2021 Antonino Scurria, Pietro Genco, and Mario Pagliaro. This article is an open access article distributed under the terms and conditions of the Creative Commons Attribution (CC BY) license (http://creativecommons.org/licenses/by/4.0/). The use, distribution or reproduction in other forums is permitted, provided the original author(s) or licensor are credited and that the original publication in this journal is cited, in accordance with accepted academic practice. No use, distribution or reproduction is permitted which does not comply with these terms.

\section{References}

[1] Druckman, C. Sicily's superior cannoli: a guide for connoisseurs and skeptics. The Wall Street Journal, 28 January, 2017
[2] Piazza, A. Sicilian cannoli - Cannoli siciliani, In Cooking with Giovanni Caboto: Regional Italian Cuisine, Ed.: Piazza, G., Biblioasis, Windsor, Ontario, Canada, 2012, p. 302

[3] Online search using the query "Sicilian cannoli" carried out on google.com, October 27, 2021.

[4] O'Leary, N. 'Sicilian Space Program' launches pastry into stratosphere, Reuters, 6 March, 2014. https://www.reuters.com/ article/us-italy-pastry/sicilian-space-program-launches-pastry-into-str atosphere-idINBREA2512X20140306 (accessed December 2, 2021).

[5] Ghosh, V.; Ziegler, G. R.; Anantheswaran, R. C. Fat, moisture, and ethanol migration through chocolates and confectionary coatings. Crit. Rev. Food Sci. Nutr. 2002, 42, 583-626.

[6] Del Nobile, M. A.; Muratore, G.; Conte, A.; Incoronato, A. L.; Panza O. An integrated approach to extend the shelf life of a composite pastry product (cannoli). J. Food Prot. 2009, 72, 2553-2560.

[7] Rangari, V. K.; Biswas, M. C.; Tiimob, B. J.; Umerha, C. Biodegradable Polymer Blends for Food Packaging Applications. In Food Packaging: Innovations and Shelf-Life, Ed.: da Cruz, R. M. S., CRC Press, Boca Raton (FL), Chapter 7, 2019.

[8] Sicilian cannoli: history, information, interesting facts, WebFoodCulture, 2021. See at the URL: https://www.webfoodculture.com/sicilian-cannoli-history-info-interesting-facts/ (accessed December 2, 2021).

[9] Pala, C.; Scarano, C.; Venusti, M.; Sardo, D.; Casti, D.; Cossu, F.; Lamon, S.; Spanu, V.; Ibba, M.; Marras, M.; Paba, A.; Spanu, C.; De Santis, E.P.L. Shelf life evaluation of ricotta fresca sheep cheese in modified atmosphere packaging. Ital. J. Food Saf. 2016, 5, 5502.

[10] Ha, M.; Sabherwal, M.; Duncan, E.; Stevens, S.; Stockwell, P.; McConnell, M.; El-Din Bekhit, A.; Carne, A. In-depth characterization of sheep (Ovis aries) milk whey proteome and comparison with cow (Bos taurus). PLoS One 2015, 10, e0139774.

[11] Salvatore, E.; Pes, M.; Falchi, G.; Pagnozzi, D.; Furesi, S.; Fiori, M.; Roggio, T.; Addis, M.F.; Pirisi, A. Effect of whey concentration on protein recovery in fresh ovine ricotta cheese. J. Dairy Sci. 2014, 97, 4686-4694.

[12] Yamauchi, K.; Shimizu, M.; Kamiya, T. Emulsifying properties of whey protein. J. Food Sci. 2006, 45, 1237-1242.

[13] Pagliaro, M. Glycerol, Elsevier, Amsterdam, the Netherlands, 2017.

[14] Pagliaro, M.; Rossi, M. Glycerol: Properties and Production. In The Future of Glycerol, RSC Publishing, Cambridge, Great Britain, 2010, pp. 1-28.

[15] Dickinson, E. Properties of emulsions stabilized with milk proteins: overview of some recent developments. J. Dairy Sci. 1997, 80, 2607-2619.

[16] EFSA Panel on Food Additives and Nutrient Sources added to Food, Re-evaluation of glycerol (E 422) as a food additive. EFSA J. 2017, 15, 4720.

[17] del Bono, M. Dizionario Siciliano-Italiano-Latino, Vol. 1, Stamperia di Giuseppe Gramignani, Palermo, 1751, p. 142.

[18] Wieruszowski, Roger II of Sicily, rex-tyrannus, in twelfth-century political thou H. ght. Speculum 1963, 38, 46-78.

[19] Pagliaro, M.; Meneguzzo, F. Que faire? A bioeconomy and solar Energy institute at Italy's Research Council in the context of the global transition to the solar economy, Chem.-Eur. J. 2017, 23 , 15276-15282. 